\title{
Orbital fibrosis in a mouse model of Graves' disease induced by genetic immunization of thyrotropin receptor cDNA
}

\author{
Shuang-Xia Zhao, Shanli Tsui ${ }^{1}$, Anthony Cheung, Raymond S Douglas ${ }^{2,3}$, Terry J Smith ${ }^{2,3}$ and J Paul Banga \\ Department of Diabetes and Endocrinology, King's College London School of Medicine, London, UK \\ ${ }^{1}$ Department of Medicine, Harbor-University of California, Los Angeles, California, USA \\ Departments of ${ }^{2}$ Ophthalmology and Visual Sciences and ${ }^{3}$ Internal Medicine, University of Michigan Medical School, Ann Arbor, Wisconsin, USA \\ (Correspondence should be addressed to J P Banga who is now at Division of Diabetes and Nutritional Sciences, King's College London School of Medicine, \\ 123 Coldharbour Lane, London SE5 9NU, UK; Email: paul.banga@kcl.ac.uk)
}

\begin{abstract}
The TSH receptor (TSHR) is the critical target for antibody production in Graves' disease (GD). Insulin-like growth factor 1 receptor (IGF1R) has been proposed as a second autoantigen in complications of GD such as orbitopathy. We attempted to induce orbital tissue remodeling in mice undergoing immunizations with plasmids encoding TSHR and IGF1R delivered by in vivo skeletal muscle electroporation, a procedure known to give a sustained, long-term antibody response. Female $B A L B / c$ mice were challenged with TSHR A-subunit or IGF1R $\alpha$ subunit plasmid by injection and electroporation. Mice challenged with TSHR A-subunit plasmid resulted in high frequency $(75 \%)$ of hyperthyroidism and thyroid-stimulating antibodies. But strikingly, immunization with TSHR A-subunit plasmid also elicited antibody to IGF1R $\alpha$ subunit. Mice challenged in the same manner with IGF1R $\alpha$ subunit plasmid produced
\end{abstract}

strong antibody responses to IGF1R, but did not undergo any changes in phenotype. Simultaneous challenge by double antigen immunization with the two plasmids in distant anatomical sites reduced the incidence of hyperthyroidism, potentially as a consequence of antigenic competition. Thyroid glands from the TSHR A-subunit plasmidchallenged group were enlarged with patchy microscopic infiltrates. Histological analysis of the orbital tissues demonstrated moderate connective tissue fibrosis and deposition of Masson's trichrome staining material. Our findings imply that immunization with TSHR A-subunit plasmid leads to generation of IGF1R antibodies, which together with thyroid-stimulating antibodies may precipitate remodeling of orbital tissue, raising our understanding of its close association with GD.

Journal of Endocrinology (2011) 210, 369-377

\section{Introduction}

Inflammation and remodeling of orbital tissues commonly occur in the autoimmune thyroid disease, Graves' disease (GD). This process is referred to as thyroid eye disease, thyroid-associated ophthalmopathy, or Graves' orbitopathy (GO) (Perros \& Krassas 2009, Bahn 2010, Naik et al. 2010). In GD, thyroid-stimulating antibodies (TSAbs) directed against the TSH receptor (TSHR) activate the thyroid gland, leading to excessive production of thyroid hormone and thyrotoxicosis (Rees Smith et al. 1988). TSAbs may also target TSHR expressed in extra-thyroidal tissues (Bell et al. 2000, Zhang et al. 2009). The characteristic tissue remodeling in GO may be associated with enhanced adipogenesis and deposition of glycosaminoglycans. It is currently believed that these changes culminate in protrusion of the eyes (Bell et al. 2000, Zhang et al. 2009, Naik et al. 2010). The pathogenic role of TSHR as a target antigen is well established in GD. However, in GO, the extra-ocular muscles do not express TSHR (Paschke et al. 1993), but a number of other eye muscle antigens have been characterized with serum antibodies from patients with GO (Gopinath et al. 2006). In addition, insulin-like growth factor receptor 1 (IGF1R) has been recognized as a relevant antigen in the pathogenesis of GO, perhaps serving as a second autoantigen (Weightman et al. 1993, Pritchard et al. 2003, Drexhage 2006). Resident fibroblasts and adipose tissue express functional TSHR and IGF1R (Bell et al. 2000, Zhang et al. 2009) and represent the key participants in orbital tissue remodeling in GO (Smith 2003), Recently, bone marrow-derived CD34 ${ }^{+}$ fibrocytes have been detected among the fibroblasts inhabiting the orbit in GO, which express both receptors (Douglas et al. 2010, Kahaly 2010). Fibrocytes possess unique properties that render them well suited for participation in the pathological changes occurring in GO. Moreover, the recent finding that TSHR and IGF1R are complexed in thyrocytes and orbital fibroblasts suggests a mechanism to allow cross talk in signaling, which may provide additional, but to date undermined, roles in the pathogenesis of GO (Tsui et al. 2008).

GD occurs spontaneously in human beings but does not appear to do so in any other species (Dagdelen et al. 2009). 
Development of experimental models of GD has been attempted by different procedures, including immunization with TSHR fusion proteins purified from Escherichia coli (E. coli) or transfer of cells expressing TSHR and major histocompatibility complex (MHC) class II antigens (Costagliola et al. 1996, Shimojo et al. 1996), but the most reproducible models rely on genetic immunizations requiring in vivo expression of TSHR (reviewed in Dagdelen et al. (2009)). In attempts to develop GO in mice, Many et al. (1999) reported a model based on transfer of TSHR-primed splenic T cells from mice immunized with TSHR fusion proteins to naïve syngeneic animals, which showed remarkable orbital changes manifest in BALB/c mice. Orbital pathology was studied in fixed sections and by immunohistochemistry in frozen sections using leukocyte-specific antibodies. The orbital tissue showed dissociation of orbital muscle bundles by edema, accompanied by accumulation of glycosaminoglycans and adipose tissue together with an inflammatory infiltrate of T and $B$ cells and macrophages (Many et al. 1999). In a separate study from the same group, but using genetic immunization to induce hyperthyroidism in outbred mice, scattered mast cells were also reported in the orbital muscle tissues (Costagliola et al. 2000). Importantly, the reported findings have been difficult to substantiate (Baker et al. 2005). In another study, accumulation of mast cells in orbital tissue was also reported after genetic immunization of outbred mice with TSHR and G2s cDNA (Yamada et al. 2002).

In studies using adenovirus encoding TSHR A-subunit (amino acids 22-289; Chen et al. 2003), we were unable to provoke either thyroiditis or orbital inflammation, but that strategy induced very strong thyroid-stimulating antibodies (TSAbs) associated with a high incidence of hyperthyroidism (Gilbert et al. 2006). Recently, improvements in the delivery of plasmid encoding TSHR have relied on plasmid injection combined with muscle electroporation in vivo (Kaneda et al. 2007). The electroporation technique results in enhanced transfection efficiency, induces a strong antibody response to TSHR, and results in frequent hyperthyroidism. Importantly, this model generates long lasting immunity (Kaneda et al. 2007), which may be critical for the development of tissue pathology. We now report that injection of plasmids encoding human TSHR A-subunit combined with electroporation results in hyperthyroidism, generation of TSAbs, appearance of antibodies to IGF1R, microscopic thyroid infiltrates, and moderate orbital fibrosis.

Recently, Eckstein and colleagues have reported the trafficking of leukocytes into orbital tissue in C57/BL6 mice following immunization with TSHR A-subunit encoding adenovirus or TSHR plasmid following depletion of regulatory $\mathrm{T}$ cells (Johnson et al. 2010, Ziler et al. 2010). The orbital inflammation data in immune C57/BL6 mice, together with our findings of orbital fibrosis in immune $\mathrm{BALB} / \mathrm{c}$ mice, suggest that orbital phenotypic alterations characteristic of human GD can be induced in inbred mice undergoing experimental hyperthyroidism, which will facilitate our understanding of pathogenesis of GO.

\section{Materials and Methods}

\section{Animals}

$\mathrm{BALB} / \mathrm{c}$ female mice (age 8-10 weeks) were purchased from Harlan (Loughborough, UK) Ltd. Animals were housed under conventional conditions in cages with filter top lids, with food made available ad libitum. All animal experiments were conducted according to UK Home Office and King's College London regulations under full veterinary welfare care.

\section{Cloning and preparation of plasmid DNA}

Expression plasmids included i) pTriEx-1.1 Neo, a multisystem expression plasmid (Novagen, Leicestershire, UK) and ii) pCAGGS, a high-efficiency mammalian expression vector (Niwa et al. 1991) (gift from Professor D J Wells, Imperial College London). Human TSHR A-subunit (amino acid residues 22-289) and human IGF1R $\alpha$ subunit (741 amino acids) were amplified for cloning. TSHR A-subunit cDNA region was cloned into $\mathrm{BamHI}$ and NotI restriction sites in pTriEx-1.1 Neo by amplification from pcDNA3.1-human TSHR plasmid (Rao et al. 2003) using forward primer 5'-CGCGGATCCATGAGGCGATTTCGGAGG-3' and reverse primer $5^{\prime}$-ATAAGAA TGCGGCCGCTTACTGATTCTTAAAAGCACAGC-3' ${ }^{\prime}$ and KOD HiFi DNA polymerase (Novagen) and cloned into pGEM-T easy vector. The cDNA was excised and subcloned into BamHI and NotI-digested pTriEx-1.1 NeopTriEx-1.1 Neo vector. Similarly, TSHR A-subunit cDNA region was cloned into EcoRI restriction sites of pCAGGS vector by amplification from human TSHR/pcDNA3.1 plasmid using forward primer $5^{\prime}$-CCGGAATTCATGAGGCGATTTCGGAGG-3' and reverse primer $5^{\prime}$-CCGGAATTCTTACTGATTCTTAAAAGCACAGC- $3^{\prime}$ and cloned into pGEM-T easy vector. The cDNA was excised and subcloned into EcoRI-digested pCAGGS vector and orientation determined. The plasmids, termed pTriEx-1.1 Neo-TSHR A-subunit and pCAGGSTSHR A-subunit, were fully sequenced in both strands.

IGF1R $\alpha$ subunit cDNA was cloned from human orbital fibroblasts (Tsui et al. 2008). Briefly, mRNA was reverse transcribed into cDNA using an Omniscript RT Kit (Qiagen). For PCR, forward primer $5^{\prime}$-GAATGAAGTCTGGCTCCGGAGG-3' and reverse $5^{\prime}$-CTCTCCGCTTCCT-TTCAGGTC- $3^{\prime}$ were used to generate a $2 \cdot 2 \mathrm{~kb}$ PCR fragment, which was then tibialis anterior (TA) cloned into pCR2.1 vector (Invitrogen) and further subcloned in-frame into a pEGFP-N1 vector (BD Biosciences, Oxford, UK) and termed pEGFP-IGF1R $\alpha-$ GFP. For generating IGF1R $\alpha$ subunit (741 amino acids) for cloning in pTriEx-1.1 NeopTriEx-1.1 Neo, the region of 2223 bp (including the stop codon) was amplified from pEGFP-IGF1R $\alpha-$ GFP with KOD HiFi DNA polymerase, forward primer with BamHI site: $5^{\prime}$-CGCGGATCCATGAAGTCTGGCTCCGG-3' and reverse primer with NotI site: 5'-ATAAGAATGCGGCCGCTTATCTCCGCTTCCTTT CAGG-3', 
then TA cloned into pGEM-T easy followed by subcloning into pTriEx-1.1 NeopTriEx-1.1 Neo vector (Novagen) with BamHI and NotI restriction sites. For cloning into EcoRI restriction site in pCAGGS vector, the 2223 bp region was amplified from pEGFP-IGF1R $\alpha-$ GFP with KOD HiFi DNA polymerase: forward primer $5^{\prime}$-CCGGAATTCATGAAGTCTGGCTCCGG-3 $3^{\prime}$ and reverse primer $5^{\prime}$-CCGGAATTCTT ATCTCCGCTTCCTTTCAGG-3' and then TA cloned into pGEM-T easy followed by subcloning into EcoRI-digested pCAGGS vector. The plasmids, termed pTriEx-1.1 Neo-IGF1R $\alpha$ and pCAGGS-IGF1R $\alpha$ plasmid, were fully sequenced in both strands to verify the amplified sequence.

pTriEx-1.1 Neo $\beta$-gal (Novagen) and pCAGGS $\beta$-gal were obtained from Dr D J Wells. All plasmids were grown in E. coli XL-1 Blue cells in LB medium in 2.51 cultures and purified using the QIAfilter Plasmid Giga Kit (Qiagen). Purified plasmid concentrations were measured using a Nanodrop spectrophotometer, resuspended at $1 \mathrm{mg} / \mathrm{ml}$ in sterile water, and stored at $-80{ }^{\circ} \mathrm{C}$. Single plasmid preparations were used for the entire set of injections for the group of animals.

\section{I.m. injection and in vivo electroporation of plasmid DNA}

For immunization, the parameters for electroporation were selected as described (McMahon et al. 2001). The shaved TA muscle of each hind leg of anesthetized mice was injected with $25 \mu \mathrm{l}$ plasmid $(1 \mathrm{mg} / \mathrm{ml}$ in saline). Needles were aimed caudal into the muscle. Injections were followed immediately by electroporation with an ECM 830 system (BTX Harvard Apparatus, Holliston, MA, USA) with $7 \mathrm{~mm}$ caliper electrodes at $200 \mathrm{~V} / \mathrm{cm}$. This current was applied in ten $20 \mathrm{~ms}$ square wave pulses at $1 \mathrm{~Hz}$ and resulted in marked muscle twitching. The biceps femoris (thigh) muscle of both hind legs was injected in another group of animals. This site could accommodate $50 \mu \mathrm{l}$ plasmid injection $(1 \mathrm{mg} / \mathrm{ml}$ in saline) followed immediately by electroporation. Animals recovered from anesthesia and were monitored for signs of distress. They were treated four times at 3-week intervals (Kaneda et al. 2007), bled by saphenous vein puncture at the times indicated, and/or killed. Serum samples were stored at $-80^{\circ} \mathrm{C}$ until assayed for TSAbs. Terminal samples were also analyzed for TSH-binding inhibiting antibody (TBI) and total serum thyroxine $\left(\mathrm{T}_{4}\right)$.

\section{Measurement of serum antibodies and thyroid function tests}

Anti-TSHR antibodies TBI activity was measured in serum samples following killing. Serum $(100 \mu \mathrm{l})$ was analyzed with TRAK II DYNO test human kits (ThermoScientific Biomarkers, Henningsdorf, Germany) according to the manufacturer's instructions. Results are expressed as percentage of inhibition of radiolabeled TSH binding (Rao et al. 2003, Gilbert et al. 2006). TSAbs were measured using $3 \mu \mathrm{l}$ serum in a bioassay in JP09 cells stably transfected with human TSHR. Samples were diluted in NaCl-free isotonic Hank's balanced salt solution containing $0.5 \mathrm{mM}$ isobutyl-1-methylxanthine, sucrose, and HEPES, as described (Gilbert et al. 2006). cAMP was measured by RIA in a commercial kit; total $\mathrm{T}_{4}$ was determined by RIA (ThermoScientific Biomarkers) and basal values determined from four normal $\mathrm{BALB} / \mathrm{c}$ mice (Gilbert et al. 2006).

Anti-IGF1Ra Abs were measured in a coupled in vitro transcription and translation system $(\operatorname{TnT})$ radioligand-binding assay (Tree et al. 2000, Bonifacio et al. 2010). Briefly, IGF1R $\alpha$ subunit cDNA (2223 bp) was excised with BamHI/NotI digestion from pGEM-T easy vector and cloned into pSP64 Poly(A) vector (Promega). This vector contains an SP6 promoter to yield sense strand mRNA in the presence of SP6 RNA polymerase and ribonucleotide triphosphates. In the coupled TnT system, IGF1R $\alpha$ subunit is produced as a radioactive ${ }^{35} \mathrm{~S}$-methionine-labeled nascent protein. The quality of ${ }^{35} \mathrm{~S}$-radioactivity incorporated into the translated protein was determined by precipitation with $10 \%$ trichloroacetic acid and liquid scintillation counting. Anti-IGF1R antibody was detected by overnight incubation of $5 \mu \mathrm{l}$ mouse serum with aliquots of ${ }^{35}$ S-IGF1R $\alpha$-translated protein (20 000 c.p.m.) overnight at $4{ }^{\circ} \mathrm{C}$ in immunoprecipitation buffer $(10 \mathrm{mM}$ HEPES, $150 \mathrm{mM}$ $\mathrm{NaCl}, 20 \mathrm{mM}$ methionine, $0.5 \mathrm{mg} / \mathrm{ml} \mathrm{BSA}$, and $0.5 \%$ Triton $\mathrm{X}-100, \mathrm{pH} 7 \cdot 4)$. This was layered on protein G-Sepharose, washed extensively by vacuum filtration, and radioactivity was counted. Rabbit anti-human IGF1R peptide antiserum N20 (N-terminus peptide, sc712) and antiserum C-20 (C-terminus peptide, sc-713; Santa Cruz, Santa Cruz, CA, USA) served as positive and negative controls respectively.

\section{Histology}

Thyroid-trachea preparations were fixed in 10\% buffered formalin, embedded in paraffin, and sectioned for hematoxylin and eosin ( $\mathrm{H} \& \mathrm{E})$ staining. To ensure that micro-infiltrates are not missed, the entire two lobes of the thyroid gland were sectioned serially at $4 \mu \mathrm{m}$, with the next ten serial step sections discarded, followed by retaining another set of serial section until the entire thyroid gland had been sectioned (Kong 2007). Mouse extra-ocular muscles were accessed by transcranial dissection. The entire orbital bony tissue comprising the orbital bones with the eyeball, extraocular muscles, and the optic nerve was carefully separated from the mouse and fixed in buffered $10 \%$ formalin. After $24 \mathrm{~h}$, the orbital bony tissue was placed in 10\% decalcification solution for 7 days with one change of the solution. Thereafter, the orbital tissue was embedded in the same orientation in paraffin block, serial and step sections as described above were performed starting from the lateral side (optic nerve side). In contrast to the sectioning of the entire thyroid gland, due to the 'larger' size orbital tissue, it was not possible to section the entire lateral side of the orbit. Two serial sections were collected after every ten-step sections and subjected separately to H\&E or Masson's trichrome staining. For the orbit, at least three to five sections (after ten-step sections discarded) were examined. 


\section{Statistical analysis}

Anti-IGF1R $\alpha$ Abs were deemed positive if titers were $>2$ S.D. above the mean of control mice immunized with $p$ TriEx-1.1 Neo- $\beta$-gal plasmid. TSAbs levels were expressed as the fold change compared to control sera in each experiment.

\section{Results}

\section{Assessment of immunogenicity of different plasmids}

We first evaluated the immunogenicity of the two plasmids, pTriEx-1.1 Neo or pCAGGS. BALB/c mice were injected with pTriEx-1.1 Neo or pCAGGS plasmids containing TSHR A-subunit or IGF1R $\alpha$ subunit cDNA. This was followed immediately by electroporation into both TA muscles. Animals challenged with pTriEx-1.1 Neo-TSHR A-subunit exhibited a robust generation of TSAbs following the fourth injection in four of seven mice (Fig. 1). Antibody levels peaked in individual mice at different times (Fig. 1). At killing (10 weeks after the last injection), TSAbs could be detected in two animals while one was hyperthyroid (Table 1, mouse \#4 and 5). Interestingly, TBI activity remained at a high level in all animals (Table 1). We also tested immune serum from this group of mice for antibody against IGF1R $\alpha$ subunit. Surprisingly, two mice were significantly positive for anti-IGF1R $\alpha$ subunit antibodies (Table 1, \#2 and 5). Thus, the results indicate that TSAbs induced with $p$ TriEx-1.1

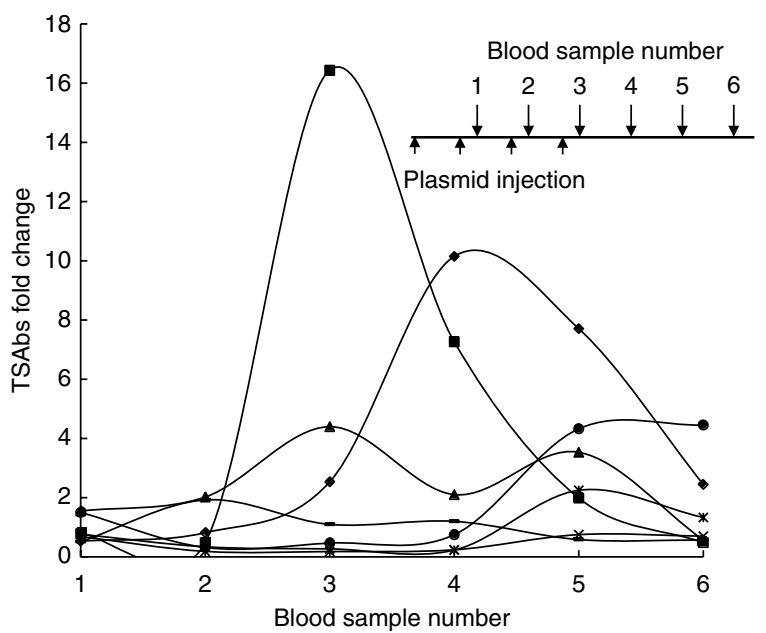

Figure 1 Time course of TSAbs in mice immunized with pTriEx-1.1 Neo-TSHR A-subunit combined with electroporation. The abscissa indicates blood sample collected 1 week after the injections and continued every 3 weeks for another 10 weeks after the last injection (see inset). The TSAbs on the ordinate are shown as fold change over the response obtained with normal serum from six mice, tested individually in the assay (different symbols indicate each individual mouse). The inset shows the immunization profile, where plasmid injections were conducted four times (indicated by small arrows) every 3 weeks apart, together with the timing of the blood sample collection (large arrows).
Neo-TSHR A-subunit immunization and electroporation group persist for at least 10 weeks after the last injection (Fig. 1). Importantly, immunization with pTriEx-1.1 Neo-TSHR A-subunit can result in the generation of antibodies to IGF1R $\alpha$ subunit.

We next tested the efficacy of the pCAGGS-TSHR A-subunit plasmid by immunization combined with electroporation. TBI activity was strongly positive in serum (10 weeks after the fourth injection) in all animals in this group ( $n=8$ mice), but remarkably all animals were negative for TSAbs and none were hyperthyroid. In addition, all pCAGGS-TSHR A-subunit challenge group animals were negative for antibody to IGF1R $\alpha$ (not shown). Thus, our findings demonstrate the superiority of pTriEx-1.1 Neo-TSHR A-subunit in inducing TSAbs and experimental hyperthyroidism. Moreover, immunization with pTriEx-1.1 Neo-TSHR A-subunit can also elicit production of antibodies to IGF1R $\alpha$ subunit.

Animals challenged with pTriEx-1.1 Neo-IGF1R $\alpha$ immunization combined with electroporation resulted in detectable anti-IGF1R $\alpha$ antibodies in all animals (Table 1). We also tested the sera from this group for antibodies to TSHR and found that they were uniformly undetectable. Moreover, no animals developed hyperthyroidism. Immunization with the different plasmid, pCAGGS-IGF1R $\alpha$, gave comparable results (data not shown). All animals immunized with the IGF1R $\alpha$ plasmids appeared healthy.

\section{Challenge with pTriEx-1.1 Neo plasmid constructs}

Preliminary analysis of the results from plasmid injections combined with electroporation indicated that pTriEx-1.1 Neo-TSHR A-subunit is effective in inducing TSAbs and hyperthyroidism, as well as induction of antibodies to IGF1R $\alpha$ subunit. Therefore, this combination immunization strategy using pTriEx-1.1Neo plasmids was used subsequently. To increase transfected muscle volume, injections were performed in biceps femoris (thigh) muscle combined with electroporation. Groups of mice were challenged in both legs with either pTriEx-1.1 Neo-TSHR A-subunit or pTriEx-1.1 Neo-IGF1R $\alpha$ alone. In addition, another group of animals received double plasmid combination by immunization in different anatomical sites, by simultaneous injection of pTriEx-1.1 Neo-TSHR A-subunit in one leg and pTriEx-1.1 Neo-IGF1R $\alpha$ in the other. These animals were killed 6 weeks after the last (fourth) injection and serum antibodies and tissue pathology were investigated. Control serum from $p$ TriEx-1.1 Neo- $\beta$-gal plasmid-immunized animals (Table 1) was used in the analysis.

The results are summarized as follows (Table 2): TSAbs were detected in 5/12 animals challenged with pTriEx-1.1 Neo-TSHR A-subunit alone with a high incidence of hyperthyroidism (8/12 mice). Strikingly, anti-IGF1R $\alpha$ subunit was also detected in $3 / 12$ animals (Table 2). In contrast, all animals challenged with IGF1R $\alpha$ alone develop high-titer antibodies to IGF1R $\alpha$, but anti-TSHR could not 
Table 1 Antibody status of individual mice at 10 weeks after last immunization with pTriEx-1.1 Neo-TSH receptor (TSHR) A-subunit or pTriEx-1.1 Neo-IGF1R $\alpha$ subunit or pTriEx-1.1 Neo- $\beta$-gal plasmid in tibialis anterior muscle combined with electroporation. The serum from pTriEx-1.1 Neo- $\beta$-gal immunized mice were tested in duplicate wells and gave values of: mouse \#16-529 and 682 c.p.m. (average

606 c.p.m.); mouse $\# 17-535$ and 659 c.p.m. (average 597 c.p.m.); mouse $\# 18-667$ and 611 c.p.m. (average 639 c.p.m.); mouse $\# 19-788$ and 1346 c.p.m. (average 1067 c.p.m.); mouse $\# 20-848$ and 880 c.p.m. (average 864 c.p.m.); mouse \#21-844 and 1344 c.p.m. (average 1089 c.p.m.). Mean +s.D. $=1269$ c.p.m. Values scoring higher than 1269 c.p.m., scored significantly positive. Values highlighted in bold, significantly positive (mean +2 s.D.)

\begin{tabular}{|c|c|c|c|c|c|}
\hline Mouse number & $\begin{array}{c}\text { Immunogen plasmid } \\
\text { pTriEx-1.1 Neo }\end{array}$ & $\begin{array}{l}\text { Anti-TSHR } \\
\quad \text { inhibition }(\%)^{\mathrm{a}}\end{array}$ & $\begin{array}{l}\text { TSAbs Fold } \\
\text { increase }^{b}\end{array}$ & $\begin{array}{l}\text { Serum total } \\
\qquad \mathbf{T}_{\mathbf{4}}(\mathrm{nmol} / \mathrm{l})^{\mathrm{C}}\end{array}$ & $\begin{array}{l}\text { Anti-IGF1R } \alpha \\
\quad \text { (c.p.m. })^{\mathrm{d}}\end{array}$ \\
\hline 1 & TSHR A-sub & 85 & $0 \cdot 6$ & 57 & 1052 \\
\hline 2 & TSHR A-sub & 88 & $0 \cdot 5$ & 58 & 1308 \\
\hline 3 & TSHR A-sub & 87 & $0 \cdot 6$ & 83 & 1117 \\
\hline 4 & TSHR A-sub & $>90$ & $4 \cdot 5$ & 132 & 1047 \\
\hline 5 & TSHR A-sub & $>90$ & $2 \cdot 4$ & 67 & 1326 \\
\hline 6 & TSHR A-sub & 79 & $0 \cdot 7$ & 47 & 1107 \\
\hline 7 & TSHR A-sub & 81 & $1 \cdot 3$ & 28 & 930 \\
\hline 8 & IGF1R $\alpha$ sub & 3 & $0 \cdot 5$ & 50 & 1924 \\
\hline 9 & IGF1R $\alpha$ sub & 5 & $0 \cdot 7$ & 64 & 1456 \\
\hline 10 & IGF1R $\alpha$ sub & 7 & $0 \cdot 7$ & 44 & 1321 \\
\hline 11 & IGF1R $\alpha$ sub & 9 & $0 \cdot 6$ & 59 & 1420 \\
\hline 12 & IGF1R $\alpha$ sub & 6 & $0 \cdot 7$ & 47 & 1245 \\
\hline 13 & IGF1R $\alpha$ sub & 5 & $0 \cdot 8$ & 48 & 2079 \\
\hline 14 & IGF1R $\alpha$ sub & 3 & $1 \cdot 1$ & 35 & 1770 \\
\hline 15 & IGF1R $\alpha$ sub & 6 & $1 \cdot 9$ & 64 & 3009 \\
\hline 16 & $\beta-G a l$ & ND & - & 62 & 606 \\
\hline 17 & $\beta$-Gal & ND & - & 81 & 597 \\
\hline 18 & $\beta$-Gal & ND & - & 72 & 639 \\
\hline 19 & $\beta$-Gal & ND & - & 58 & 1067 \\
\hline 20 & $\beta$-Gal & ND & - & 72 & 864 \\
\hline 21 & $\beta$-Gal & ND & - & 69 & 1089 \\
\hline \multicolumn{6}{|c|}{ Controls IGF1R assay } \\
\hline Positive & Serum N20 (sc-712) & - & - & - & 11328 \\
\hline Negative & Serum C20 (sc-713) & - & - & - & 694 \\
\hline
\end{tabular}

ND, not determined.

apercentage of inhibition of ${ }^{125}$ I-TSH binding in radioreceptor TRAK assay (ThermoScientific Biomarkers).

b Thyroid-stimulating antibody (TSAb) assay in JP09 cells. Fold-increase over serum from pTriEx-1.1 Neo- $\beta$-gal immunized mice - all serum samples were measured in duplicate wells, the average cAMP values for serum from the six $\beta$-gal plasmid immunized mice were $0 \cdot 65,0 \cdot 98,0 \cdot 84,0 \cdot 58,0 \cdot 77$, and $0.57 \mathrm{pmols} / \mathrm{ml}$. With a mean of $0.73 \mathrm{pmol} / \mathrm{ml}$, any test serum giving values higher than three fold mean value $(2 \cdot 19 \mathrm{pmols} / \mathrm{ml}) \mathrm{were}$ considered positive. In the assay, stimulation with suboptimal dose of bTSH $(0 \cdot 8 \mathrm{U} / \mathrm{ml})$ and a thyroid-stimulating $\mathrm{lgG} \mathrm{mAb}(\mathrm{KSAb} 1,10 \mu \mathrm{g} / \mathrm{ml}) \mathrm{gave} 27$ and $27 \cdot 5 \mathrm{pmols} / \mathrm{ml} \mathrm{cAMP}$ respectively.

${ }^{\mathrm{C}}$ Total $\mathrm{T}_{4}$ : pTriEx-1.1 Neo- $\beta$-gal mice, Mean +s.D. $=85 \cdot 9$. Higher values scored significantly positive.

${ }^{\mathrm{d}}$ Anti-IGF1R $\alpha$ samples, mean of duplicates (c.p.m.). The positive and negative control rabbit anti-IGF1R peptide antiserum is indicated. The c.p.m. of individual triplicate wells for serum N20 (25 $\mu$ g) were 10128, 14403, and 9454 c.p.m. (average 11328 c.p.m.); for serum C20 (25 $\mu$ g) were 595 , 641 and 847 c.p.m. (average 694 c.p.m.).

be detected (0/12 animals) and none developed hyperthyroidism. Challenge with double plasmid immunization in different anatomical sites resulted in fewer hyperthyroid mice (2/12 animals) compared with pTriEx-1.1 Neo-TSHR A-subunit alone, which may be related to antigenic competition (Hunt et al. 2001; Table 2).

\section{Assessment of pathology in the thyroid and orbital tissue}

Thyroid glands from pTriEx-1.1 Neo-TSHR A-subunitchallenged mice were enlarged when compared to those from animals immunized with pTriEx-1.1 Neo-IGF1 $\alpha$ alone. We then assessed the histopathology of all the thyroid glands in the three groups of immune animals (Table 2). In the group immunized with pTriEx-1.1 Neo-TSHR A-subunit alone, 5/12 thyroids exhibited pathological changes (Table 2, animals \#1, 2, 4, 5, and 11), characterized by micro-infiltrates (Fig. 2a). Three of the 12 thyroids from those animals immunized in different anatomical sites with pTriEx-1.1 Neo-TSHR A-subunit and pTriEx-1.1 Neo-IGF1R $\alpha$ showed these changes (Table 2, animals \#27, 28 and 31). In those animals exhibiting thyroid abnormalities, examination of orbital tissue revealed fibrosis in the muscle tissue following H\&E staining (Fig. 2b), together with material staining with Masson's trichrome (Fig. 2c). Inspection of orbital tissue from control mice revealed no abnormalities (Fig. 2d and e). Orbital tissue from an immune animal, the thyroid of which was normal was also unremarkable (Table 2, animal \#12). Thyroid glands from all animals in the group challenged with IGF1R $\alpha$ plasmid alone were normal, as was the orbital tissue (Table 2, animals \#17 and 21). 


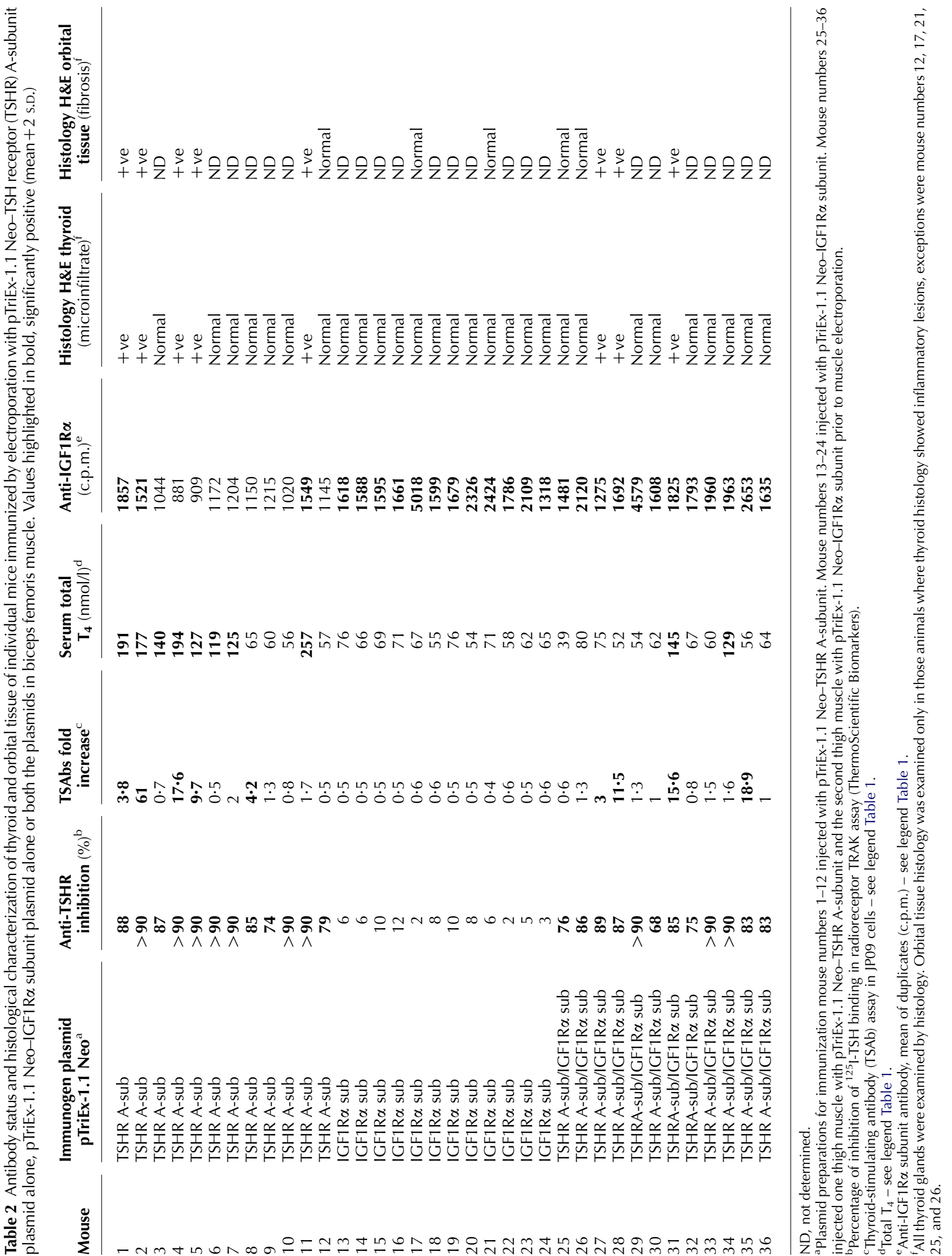



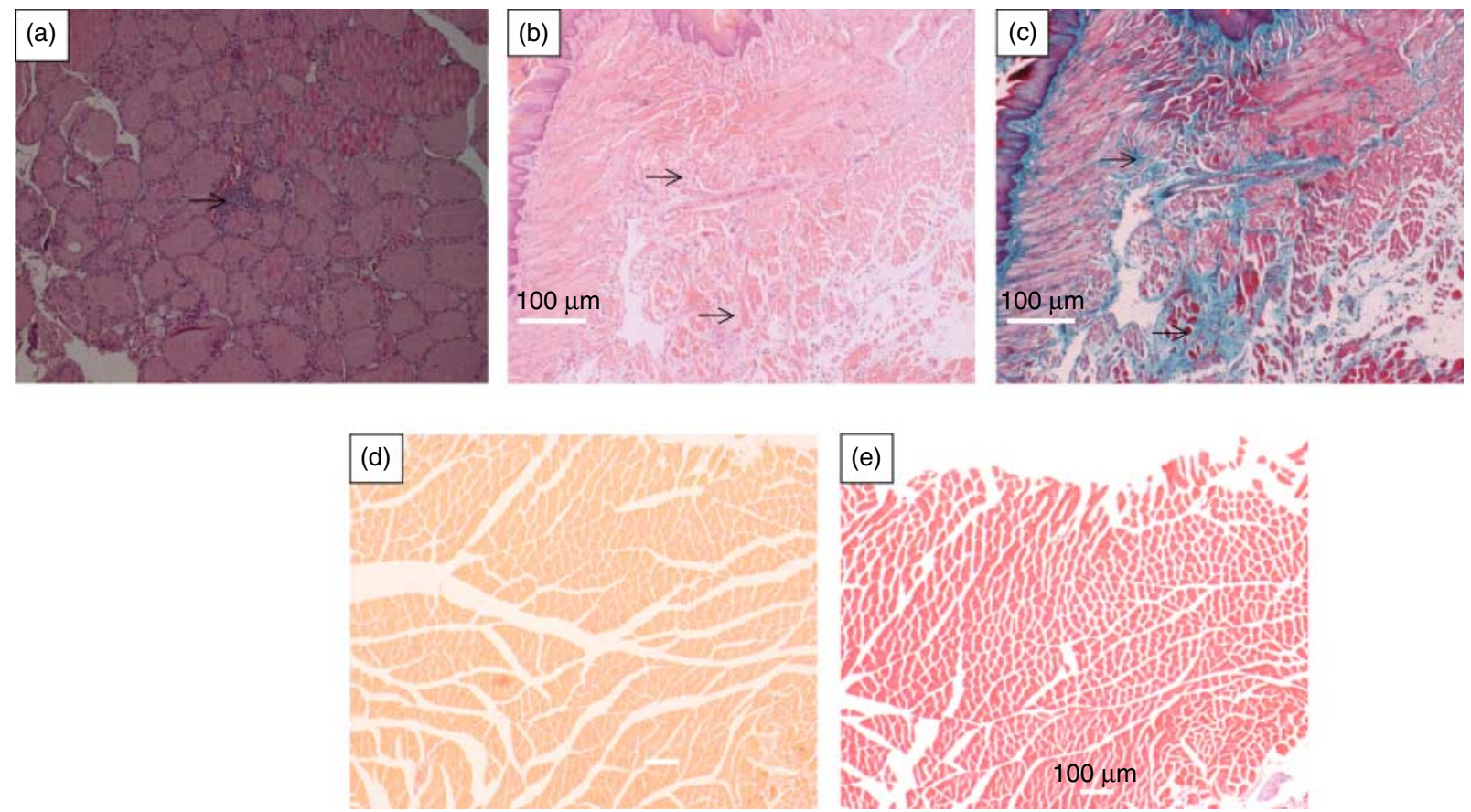

Figure 2 Histological analysis of the orbital and thyroid tissue to show pathology of the organs after challenge with pTriEx-1.1 Neo-TSHR A-subunit alone. (a) Hematoxylin and eosin (H\&E) staining of thyroid gland from mouse number 2 (Table 2) to show mononuclear cell microinfiltrate next to a blood vessel (arrowed). (b) Orbital section from the same mouse, H\&E staining to show extensive fibrosis in the muscle tissue and (c) Serial section from (b) after Masson's trichrome staining to show deposition of collagen and glycosaminoglycans (arrowed). (d) Orbital section of normal orbit, H\&E staining and (e) Serial section from (d) after Masson's trichrome staining. Although ( $b$ and $c$ ) and ( $d$ and e) are serial sections from respective wax blocks, different staining procedures result in different contractions of the section, hence do not align exactly. Magnification (a) $\times 100$; (b and c) $\times 200$; $(d$ and e) $\times 100$. Full colour version of this figure available via http://dx.doi.org/10.1530/JOE-11-0162.

\section{Discussion}

From the observations made in the two studies presented here, several novel findings emerge. We demonstrate alterations in orbital tissues from $\mathrm{BALB} / \mathrm{c}$ mice immunized with pTriEx-1.1 Neo-TSHR A-subunit using i.m. injection combined with electroporation. Unexpectedly, immunization with pTriEx-1.1 Neo-TSHR A-subunit provokes the production of antibodies specific for IGF1R $\alpha$ subunit. In addition to thyroid inflammation, our model shows orbital changes. The lymphocyte infiltration in thyroid appeared as small microinfiltrates (Kong 2007) with patchy distribution. Orbital tissue exhibited tissue remodeling and fibrosis, which stained positively with Masson's trichrome. These changes, suggesting accumulation of collagen and glycosaminoglycan, were absent in control orbital tissue. In contrast, immunization with IGF1R $\alpha$ plasmid efficiently induced antiIGF1R $\alpha$ antibodies but was insufficient to promote any tissue pathology. Only animals with thyroid infiltrate appear to exhibit orbital pathology. These exhibit partial fidelity with those found in human GO. We could not identify cellular infiltrates in the orbits.

The current studies build on and refine the findings of Kaneda et al. (2007), who first reported the combined plasmid injection and electroporation approach to promoting experimental GD. That report achieved efficient induction of TSAbs and hyperthyroidism, although lymphocyte infiltration of the thyroid was absent and orbital tissues were not examined (Kaneda et al. 2007). Explanation for the differences between this study (Kaneda et al. 2007) and the results reported herein remains incomplete, and several possibilities exist. Thyroid enlargement was observed in some animals in both studies but lymphocyte infiltrates were scant, suggesting the need for sectioning entire thyroid glands (Kong 2007). The presence of thyroid inflammation in our study might relate to the different plasmids used (Kaneda et al. 2007). In contrast to hyperthyroidism and TSAbs following immunization with $p$ TriEx-1.1 NeoTSHR A-subunit, neither was found using pCAGGS-TSHR A-subunit. This finding implies that each plasmid could contribute differentially to the immune responses directed against TSHR A-subunit, a finding also reported (Kaneda et al. 2007). In addition, the choice of electrodes used for electroporation can strongly influence transfection efficiency (Hunt et al. 2001, Cemazar et al. 2006). Calliper plate electrodes, such as those used here, provide a more uniform electrical field over a wider area of the muscle compared to needle electrodes (Kaneda et al. 2007), which in turn could influence immune responses (Cemazar et al. 2006, Wells et al. 2008). 
Other factors potentially contributing to the disease phenotype in our new model could result from the peculiarities of the microbial environment. Our animals were housed in conventional clean rooms (with the full range of commensal bacteria and normal gut microflora), rather than the specific pathogen-free conditions used in some studies (Kaneda et al. 2007). In related studies from this laboratory, when immunization with adenovirus expressing TSHR A-subunit was utilized, the incidence of hyperthyroidism occurring in animals housed in clean rooms (Gilbert et al. 2006) was congruent with the findings of animals housed in pathogen-free conditions (Chen et al. 2003, Mizutori et al. 2006). Indeed, these earlier studies using the adenovirus model uniformly failed to exhibit thyroiditis, suggesting that clean versus pathogen-free housing conditions do not fully account for our divergent observations.

Several authors have suggested a potential role for antibodies against IGF1R playing a pathogenic role in GO (Weightman et al. 1993, Pritchard et al. 2003, Smith 2003, Drexhage 2006). While such a scenario clearly explains the association of the condition with GD, it has proven challenging to study the IGF1R antibodies in GO (Pritchard et al. 2003, Naik et al. 2010). Indeed, it is worth emphasizing that despite their potential intrinsic role in orbital pathology (Smith 2003, Drexhage 2006), the antigen(s)-stimulating pathogenic B cell clones to generate anti-IGF1R antibody remain incompletely defined (Smith 2003, Naik et al. 2010). In this study, we observed the presence of antibodies to IGF1R $\alpha$ subunit following immunization with TSHR A-subunit. One explanation for the anti-IGF1R $\alpha$ antibodies following immunization with TSHR A-subunit may be related to the fact that TSHR and IGF1R are physically associated (Tsui et al. 2008). Immunization with TSHR A-subunit appears to be a requirement for thyroid and orbit inflammation, since immunization with IGF1R $\alpha$ alone was inadequate for generating a disease phenotype. On this basis, we now speculate that the antibody to IGF1R $\alpha$ following immunization with TSHR A-subunit may differ from that induced following immunization with IGF1R $\alpha$ itself. That scenario would imply that IGF1R $\alpha$ antibodies induced by TSHR A-subunit are pathogenic, either acting alone or in combination with TSAbs, as suggested by Smith et al. (2008).

Although seemingly clear-cut, our results raise a number of questions. For instance, what factors drive anti-IGF1R $\alpha$ antibody production after challenge with TSHR A-subunit? Is expansion of anti-IGF1R $\alpha$ B cell clones driven by TSHR limited to thyroid and orbit or is it distributed widely? Is it related to the physical interactions between TSHR and IGF1R (Tsui et al. 2008). Or, is there immune cross-reactivity between TSHR A-subunit and IGF1R $\alpha$ subunit?

Recently, Eckstein et al. have reported trafficking and accumulation of leukocytes into orbital tissue in female C57/BL6 mice following immunization with TSHR A-subunit encoding adenovirus or TSHR plasmid following depletion of regulatory T cells (Johnson et al. 2010, Ziler et al. 2010). The orbital infiltrates comprised $\mathrm{F} 4 / 80^{+}$macrophages and $\mathrm{CD}^{+}{ }^{+}$lymphocytes, confirming the role of autoimmunity against TSHR in orbital inflammation. Importantly, C57/BL6 mice were superior in susceptibility to orbital infiltration to BALB/c mice (Johnson et al. 2010, Ziler et al. 2010). The development of these new models should facilitate our understanding of the molecular and cellular basis of GO and its close association with GD. It may also allow testing of new therapeutic targets in early stages of this debilitating condition (Banga et al. 2008, Naik et al. 2008).

\section{Declaration of interest}

The authors declare that there is no conflict of interest that could be perceived as prejudicing the impartiality of the research reported.

\section{Funding}

This project was supported by a grant from the Wellcome Trust (UK) and by the National Institutes of Health grants EY08976, EY011708, and DK0063121.

\section{Acknowledgements}

We enthusiastically thank Prof. Dominic Wells (Imperial College London) for his hands-on help and advice on the mouse leg muscle electroporation procedure and continuous support throughout the project. Equally, the contributions from Prof. Yi Chi Kong (Wayne State University) in providing detailed protocols for studying microinfiltrates in thyroid gland pathology have been invaluable. We also thank Dr Michael Christie (King's College London) for providing the facilities in his laboratory for the Transcription and Translation assay. Finally, we thank Dr Zareen Khan and staff in Histopathology, Department of King's College Hospital NHS Foundation Trust for interpretation of the histological sections and assistance with sectioning respectively.

\section{References}

Bahn R 2010 Graves' ophthalmopathy. New England Journal of Medicine 362 726-738. (doi:10.1056/NEJMra0905750)

Baker G, Mazziotti G, von Ruhland C \& Ludgate M 2005 Reevaluating thyrotropin receptor induced mouse models of Graves' disease and ophthalmopathy. Endocrinology 46 835-844.

Banga JP, Nielsen CH, Gilbert JA, El Fassi D \& Hegedus L 2008 Application of new therapies in Graves' disease and thyroid associated ophthalmopathy: animal models and translation to human clinical trials. Thyroid 18 973-981. (doi:10.1089/thy.2007.0406)

Bell A, Gagnon A, Grunder L, Parikh SJ, Smith TJ \& Sorisky A 2000 Functional TSH receptor in human abdominal preadipocytes and orbital fibroblasts. American Journal of Physiology. Cell Physiology 279 C335-C340.

Bonifacio E, Yu L, Williams A, Eisenbarth GS, Bingley PJ, Marconina SM, Adler K, Ziegler A, Mueller PW, Schatz DA et al. 2010 Harmonization of glutamic acid decarboxylase and islet antigen-2 autoantibody assays for National Institute of Diabetes and Digestive and Kidney Diseases Consortia. Journal of Clinical Endocrinology and Metabolism 95 3360-3367. (doi:10.1210/jc.2010-0293)

Cemazar M, Golzio M, Sersa G, Rols MP \& Teissie R 2006 Electricallyassisted nucleic acids delivery to tissues in vivo: where do we stand. Current Pharmaceutical Design 12 3817-3825. (doi:10.2174/138161206778559740) 
Chen CR, Pichurin P, Nagayama Y, Latrofa B, Rapoport B \& McLachlan SM 2003 The thyrotropin receptor autoantigen in Graves' disease is the culprit as well as the victim. Journal of Clinical Investigation 111 1897-1904.

Costagliola S, Many MC, Salmans-Falys M, Vassart G \& Ludgate M 1996 Transfer of thyroiditis, with syngeneic spleen-cells sensitized with the human thyrotropin receptor, to naive $\mathrm{BALB} / \mathrm{c}$ and NOD mice. Endocrinology 135 4637-4643. (doi:10.1210/en.137.11.4637)

Costagliola S, Many MC, Denef JF, Pohlenz J, Refetoff S \& Vassart G 2000 Genetic immunization of outbred mice with thyrotropin receptor cDNA provides a model of Graves' disease. Journal of Clinical Investigation 105 803-811. (doi:10.1172/JCI7665)

Dagdelen S, Kong YC \& Banga JP 2009 Towards better models of Graves' disease. Endocrinology and Metabolism Clinics of North America 38 343-354. (doi:10.1016/j.ecl.2009.01.003)

Douglas RS, Afifiyan NF, Hwang CJ, Chong K, Haider U, Richards P, Gianoukakis AG \& Smith TJ 2010 Increased generation of fibrocytes in thyroid-associated ophthalmopathy. Journal of Clinical Endocrinology and Metabolism 95 430-438. (doi:10.1210/jc.2009-1614)

Drexhage HA 2006 Are there more than antibodies to the thyroid stimulating hormone receptor than meets the eye in Graves' disease. Endocrinology 147 9-12. (doi:10.1210/en.2005-1305)

Gilbert JA, Gianoukakis AG, Salehi S, Moorhead J, Rao PV, Khan MZ, McGregor AM, Smith TJ \& Banga JP 2006 Monoclonal pathogenic antibodies to the TSH receptor in Graves' disease with potent thyroid stimulating activity, but differential blocking activity activate multiple signaling pathways. Journal of Immunology 176 5084-5092.

Gopinath B, Musselman R, Beard N, El-Kaissi S, Tani J, Adams CL \& Wall JR 2006 Antibodies targeting the calcium binding skeletal muscle protein calsequestrin are specific markers of ophthalmopathy and sensitive indicators of ocular myopathy in patients with Graves' disease. Clinical Experimental Immunology 145 56-62. (doi:10.1111/j.1365-2249.2006. 03110.x)

Hunt JD, Brown LE \& Jackson DC 2001 Antigenic competition. In: Encyclopedia of Life Sciences. John Wiley \& Sons. (doi:10.1038/npg.els. 0006101).

Johnson KT, Ziler B, Thanos M, Carpineteiro A, Schmid KW, Minich W, Gulbins E, Nagayama Y \& Eckstein A 2010 Immunization of C57/BL6 and $\mathrm{BALb} / \mathrm{c}$ with adenoviral TSHR 289 causes significant infiltration of orbital tissues with macrophages and $\mathrm{T}$ lymphocytes. International Thyroid Congress. Abstract OC-048.

Kahaly GJ 2010 The thyrocyte-fibrocyte link: closing the loop in the pathogenesis of Graves' disease. Journal of Clinical Endocrinology and Metabolism 95 62-65. (doi:10.1210/jc.2009-2405)

Kaneda T, Honda A, Hakozaki A, Fuse T, Muto A \& Yoshida T 2007 An improved Graves' disease model established by using in vivo electroporation exhibited long-term immunity to hyperthyroidism in $\mathrm{BALB} / \mathrm{c}$ mice. Endocrinology 148 2335-2344. (doi:10.1210/en.2006-1077)

Kong YC 2007 Experimental autoimmune thyroiditis in the mouse. Current Protocols in Immunology. Chapter 15, Unit 15. 7.

Many MC, Costagliola S, Detrait M, Denef JF, Vassart G \& Ludgate M 1999 Development of an animal model of autoimmune thyroid disease. Journal of Immunology 162 4966-4974.

McMahon JM, Signori E, Wells KE, Fazio V \& Wells DJ 2001 Optimisation of electrotransfer of plasmid into muscle by pretreatment with hyaluronidase increased expression with reduced muscle damage. Gene Therapy 8 1264-1270. (doi:10.1038/sj.gt.3301522)

Mizutori Y, Saitoh O, Eguchi K \& Nagayama Y 2006 Adenovirus encoding the thyrotropin receptor A-subunit improves the efficacy of dendritic cellinduced Graves' hyperthyroidism in mice. Journal of Autoimmunity 26 32-36. (doi:10.1016/j.jaut.2005.08.008)

Naik V, Khadavi N, Naik MN, Hwang C, Goldberg RA, Tsirbas A, Smith TJ \& Douglas RS 2008 Biologic therapeutics in thyroid associated ophthalmopathy: translating disease mechanisms into therapy. Thyroid 18 967-971. (doi:10.1089/thy.2007.0403)

Naik VM, Naik MN, Goldberg RA, Smith TJ \& Douglas RS 2010 Immunopathogenesis of thyroid eye disease: emerging paradigms. Survey of Ophthalmology 55 215-226. (doi:10.1016/j.survophthal.2009.06.009)
Niwa H, Yamamura K \& Miyazaki J 1991 Efficient selection for highexpression transfectants with a novel eukaryotic vector. Gene 18 193-200. (doi:10.1016/0378-1119(91)90434-D)

Paschke R, Elisei R, Vassart G \& Ludgate M 1993 Lack of evidence supporting the presence of mRNA for the thyrotropin receptor in extraocular muscle. Journal of Endocrinological Investigation 16 329-332.

Perros P \& Krassas GE 2009 Graves' orbitopathy: a perspective. Nature Reviews. Endocrinology 5 312-318. (doi:10.1038/nrendo.2009.61)

Pritchard J, Han R, Horst N, Cruikshank WW \& Smith TJ 2003 Immunoglobulin activation of $\mathrm{T}$ cell chemoattractant expression in fibroblasts from patients with Graves' disease is mediated through the insulin-like growth factor I receptor pathway. Journal of Immunology $\mathbf{1 7 0}$ 6348-6354.

Rao PV, Watson PF, Weetman AP, Carayanniotis G \& Banga JP 2003 Contrasting activities of thyrotroin receptor antibodies in experimental models of Graves' disease induced by injection of transfected fibroblasts or deoxyribonucleic acid vaccination. Endocrinology 144 260-266. (doi:10. 1210/en.2002-220688)

Rees Smith B, McLachlan SM \& Furmaniak J 1988 Autoantibodies to the thyrotropin receptor. Endocrine Reviews 9 106-121. (doi:10.1210/edrv-9-1-106)

Shimojo N, Kohno Y, Yamaguchi K, Kikuoka S, Hoshioka A, Niimi H, Hirai A, Tamura Y, Saito Y, Kohn LD et al. 1996 Induction of Graves-like disease in mice by immunization wirth fibroblasts transfected with the thyrotropin receptor and a class II molecule. PNAS 93 11074-11079. (doi:10.1073/ pnas.93.20.11074)

Smith TJ 2003 The putative role of fibroblasts in the pathogenesis of Graves' disease: evidence for the involvement of the insulin-like growth factor-1 receptor in fibroblast activation. Autoimmunity 36 409-415. (doi:10.1080/ $08916930310001603000)$

Smith TJ, Tsai CC, Shih MJ, Tsui S, Chen B, Han R, Naik V, King CS, Press C, Kamat S et al. 2008 Unique attributes of orbital fibroblasts and global alterations in IGF-1 receptor signaling could explain thyroid associated ophthalmopathy. Thyroid 18 983-988. (doi:10.1089/thy.2007.0404)

Tree TI, Morgenthaler NG, Duhindan N, Hicks KE, Madec AM, Scherbaum WA \& Banga JP 2000 Two distantly spaced amino acids in glutamic acid decarboxylase act in concert for maintainance of conformational determinants recognised by heterogeneous autoantibodies in type 1 diabetes. Diabetologia 43 881-889. (doi:10.1007/s001250051465)

Tsui S, Naik V, Hoa N, Hwang CJ, Affifiyan NF, Hikim AS, Gianoukakis AG, Douglas RS \& Smith TJ 2008 Evidence for an association between thyroid stimulating hormone and insulin-like growth factor 1 receptors: a tale of two antigens implicated in Graves' disease. Journal of Immunology 181 4397-4405.

Weightman DR, Perros P, Sherif IH \& Kendall-Taylor P 1993 Autoantibodies to IGF-1 binding sites in thyroid associated ophthalmopathy. Autoimmunity 16 251-257. (doi:10.3109/08916939309014643)

Wells KE, McMahon J, Foster H, Ferrer A \& Wells DJ 2008 Gene delivery to dystrophic muscle. Methods in Molecular Biology 423 421-431.

Yamada M, Li AW, West KA, Chang CH \& Wall JR 2002 Experimental model for ophthalmopathy in BALB/c and outbred (CD-1) mice genetically immunized with G2s and the thyrotropin receptor. Autoimmunity 35 403-413. (doi:10.1080/0891693021000026319)

Zhang L, Bowen T, Grennan-Jones F, Paddon C, Giles P, Webber J, Steadman R \& Ludgate M 2009 Thyrotropin receptor activation increases hyaluronan production in preadipocyte fibroblasts. Journal of Biological Chemistry 284 26447-26455. (doi:10.1074/jbc.M109.003616)

Ziler B, Johnson KT, Carpineteiro A, Thanos M, Schmid KW, Schott M, Gulbins E \& Eckstein A 2010 Genetic immunization of C57/BL6 mice against D633H TSHR causes specific anti-TSHR receptor activity on a cellular level and macrophage infiltration of orbital tissues. International Thyroid Congress 2010. Abstract OC-074.

Received in final form 8 June 2011

Accepted 29 June 2011

Made available online as an Accepted Preprint 29 June 2011 